\title{
ARPS E SUAS APLICAÇÕES NA ENGENHARIA CIVIL
}

\author{
ARPS AND ITS APPLICATIONS IN CIVIL ENGINEERING
}

Paulo Barral de Hollanda Gomes Vieira ${ }^{1}$

Liane da Silva Bueno ${ }^{2}$

\section{RESUMO}

Este artigo trata a respeito das Aeronaves Remotamente Pilotadas (ARPs) e suas aplicações no âmbito da Engenharia Civil. Por ser um tema relevante de uma tecnologia recente e ainda pouco referenciada bibliograficamente, fundamenta a elaboração deste material. Apresenta definições pertinentes frente o regulamento da Agência Nacional da Aviação Civil (ANAC), afim de elucidar o tema Drone. Pontua sua aplicação a partir de alguns exemplos práticos de intervenção de engenharia, e as legislações pertinentes. Assim como, explicita a importância do conhecimento e o domínio destas tecnologias contemporâneas, na qual vem contribuir para o desenvolvimento do perfil e das competências para egressos de cursos de graduação em Engenharia Civil. O que vem atender parte das expectativas das mantenedoras aos cursos de engenharia, quando se observa o potencial tecnológico de um RPA. Bem como, pontua a respeito da dinamização das decisões no processo de planejamento de determinadas obras, com o advento dos produtos resultantes, em relação as tecnologias tradicionais de aerofotogrametria. Concluindo-se, tem-se que os benefícios da aplicação do RPA na área da Engenharia Civil, vem desde a elaboração de projetos, a logística e gerenciamento de obras, análise diagnóstica de apoio a soluções de problemas de engenharia entre outros. Palavras-Chave: Aplicação da ARP, legislações, potencial tecnológico, análise diagnóstica, Engenharia Civil.

\footnotetext{
${ }^{1}$ Mestre em Engenharia Civil pela UFSC. Professor do Curso de Engenharia Civil da Universidade Regional de Blumenau (FURB). email: paulobarral@hotmail.com

2 Doutora em Engenharia de Produção e Mestre em Engenharia Civil pela UFSC. Professora do Curso de Engenharia Civil da Universidade Alto Vale do Rio do Peixe (UNIARP), Lider do Grupo de Pesquisa Inovação e Tecnologia da UNIARP no CNPQ. email: lianebueno@uniarp.edu.br
} 


\section{ABSTRACT}

This article deals with Remote Piloted Aircraft (ARPs) and their applications in the scope of Civil Engineering. As it is a relevant topic of recent technology and still little referenced in the literature, it is the basis for the preparation of this material. It presents relevant definitions according to the regulation of the National Civil Aviation Agency (ANAC), in order to clarify the Drone theme. It punctuates its application based on some practical examples of engineering intervention, and the relevant legislation. As well as, it explains the importance of knowledge and the domain of these contemporary technologies, in which it contributes to the development of the profile and skills for graduates of undergraduate courses in Civil Engineering. What comes to meet part of the expectations of maintainers to engineering courses, when observing the technological potential of an RPA. As well as, it punctuates about the dynamism of the decisions in the planning process of certain works, with the advent of the resulting products, in relation to the traditional technologies of aerophotogrammetry. In conclusion, the benefits of applying RPA in the field of Civil Engineering come from project design, logistics and construction management, diagnostic analysis to support engineering problem solutions, among others.

Keywords: ARP application, legislation, technological potential, diagnostic analysis, Civil Engineering.

\section{INTRODUÇÃO}

Este artigo apresenta material com características bibliográficas, ao fundamentar os drones como tecnologia contemporânea e sua aplicação na Engenharia Civil.

O termo drone ficou popularmente conhecido por inicialmente ser utilizado por uso civil para filmagens e fotografias. Os drones têm chamado atenção de diversos segmentos, fazendo com que as empresas entrem nesse mercado promissor buscando melhorias na execução dos seus serviços, e claro, sempre visando que suas aquisições tenham custos viáveis quanto aos seus usos (BORGES \& SILVA, 2018, p.15).

Os Drones são equipamentos de voo controlados remotamente via rádio, podendo alcançar distâncias e altitudes muito altas. O uso de tal tecnologia tem se tornado cada vez mais comum, tanto na área "recreativa" ou "não recreativa", 
como principalmente no uso comercial, profissional e militar, afinal é possível acoplar diversos outros equipamentos em sua estrutura, como por exemplo câmeras de alta definição, que permitem a captação de imagens de lugares remotos e de difícil acesso ao ser humano (VEZENTAINER, 2018, p.16).

O novo regulamento da Agência Nacional da Aviação Civil (ANAC) dividiu as aeronaves não tripuladas em aeromodelos, que são drones usados para fins recreativos, e Aeronaves Remotamente Pilotadas (ARPs), que são drones utilizados para operações comerciais, corporativas ou experimentais. Os drones de uso comercial, corporativo ou experimental foram categorizadas em 3 (três) classes, de acordo com o peso máximo de decolagem do equipamento, indo a primeira classe até os $25 \mathrm{~kg}$ (Classe 3), a segunda (Classe 2) variando de $25 \mathrm{~kg}$ a $150 \mathrm{~kg}$ e a terceira (Classe 1) faixa acima de 150kg (FEITAL, 2017, p.17).

Tratando-se de uma tecnologia recente, é interessante esclarecer que existem algumas diferenças na nomenclatura técnica usada para se referir a esses equipamentos. A seguir a Figura 1, explicita o uso recreativo e não recreativo do drone.

Figura 1: Uso recreativo e não recreativo do Drone

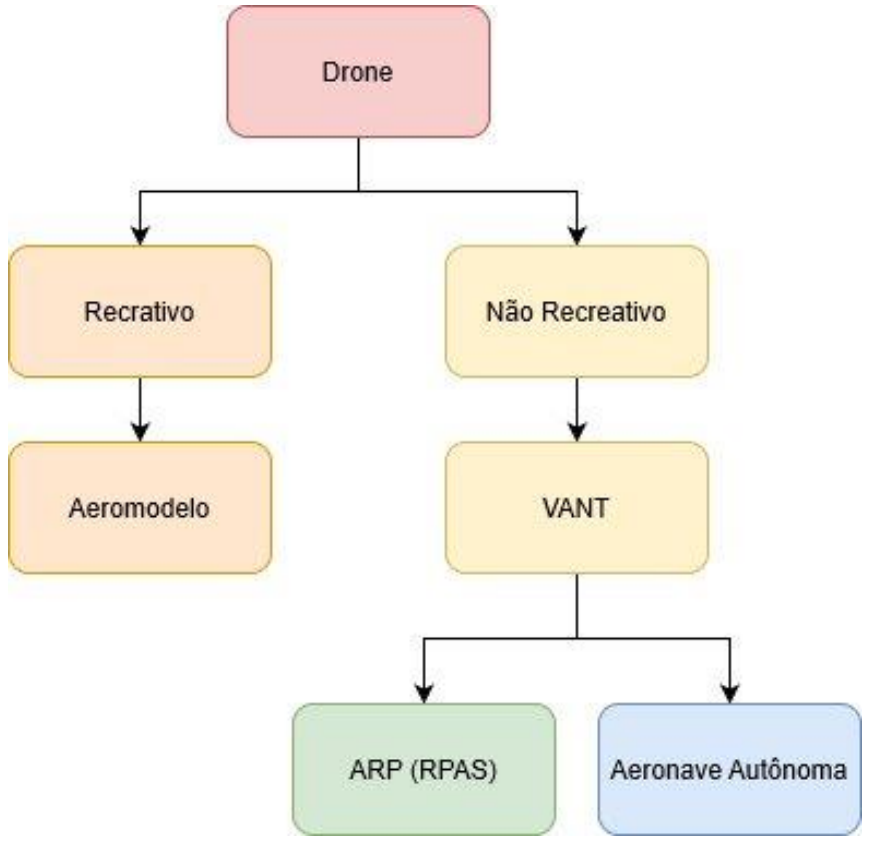

Fonte: Adaptado pelos autores, 2019 (BORGES \& SILVA, 2018, p.21) 
O termo Drone é comumente observado no meio informal de forma coloquial e que tem sua origem da língua inglesa, que significa zangão, foi oriundo do tipo de ruído ou som emitido que esses equipamentos costumam produzir em voo, ou seja, utilizado no aspecto genérico como se fosse um apelido dado pela população leiga ao equipamento usado para fins recreativo (TESTONI, 2018, p.04).

Porém, existem outras nomenclaturas (TESTONI, 2018, p.05) mais tecnicamente adequadas que são empregadas para se referir a essas aeronaves. Uma delas é o termo Remotely Piloted Aircraft Systems (RPAS) oriunda do Inglês que traduzida ao português faz referência também denominadas pelo termo Aeronave Remotamente Pilotada (ARP), termo esse comumente utilizado Departamento de Controle do Espaço Aéreo (DECEA).

Mas ainda podemos identificar o termo Veículo Aéreo Não Tripulado (VANT), ou no plural VANTs, traduzido do termo Unmanned Aerial Vehicle (UAV). Como sendo todo e qualquer tipo de aeronave que foi projetada para funcionar sem um piloto a bordo, termos esses sendo empregado em diversas literaturas técnico-científicas. O termo VANT é considerado obsoleto pela Organização da Aviação Civil Internacional $(\mathrm{OACl})$, conforme em entendimento expresso no Doc 10019, Manual On RPAS em sua 1aedição publicada no ano de 2015.

Aeronaves Autônomas são consideradas aquelas aeronaves que decole, com os parâmetros estabelecidos não podem ser mudados ou gerenciados pelo piloto. Pelo fato de ser considerada condição "sine qua non" a existência do piloto, as aeronaves (aeromodelos ou ARP/RPAS) autônomas não serão tratadas pela nossa legislação e não têm autorização para acesso ao espaço aéreo brasileiro em quaisquer condições.

Neste trabalho, tratou-se as 4 (quatro) nomenclaturas como sinônimos apesar de serem empregadas de forma diferentes tecnicamente de acordo com a interpretação ou particularidade de cada autor, órgão ou instituição aqui citada. Cabe ressaltar que estas pesquisas se delimitam em colher informações sobre quais as aplicações do uso de ARP/RAPS auxiliam melhorar a interação dos profissionais da área de engenharia com o processo construtivo em suas diversas etapas.

Sendo assim, este artigo busca reunir dados/informações com o propósito de apresentar as aplicações do uso de ARP, visando auxiliar os profissionais da área 
de Engenharia Civil.

Um artigo que ressalta a introdução de uma ferramenta de coleta de dados, cujo equipamento é relativamente recente assim como os métodos de monitoramento de inspeção visual usuais em diversos campos de atuação da Engenharia Civil.

Essas reflexões se justificam quando observa-se o mercado de trabalho na área da engenharia civil sendo cada vez mais competitivo, onde existem muitos profissionais que atuam na área sem ou com experiência, usando apenas conhecimentos empíricos (BARON, 2019, p.15). Devido à necessidade de melhorar a interação dos profissionais da área de engenharia, ao que tangem o uso de novas tecnologias, tem-se o uso de ARP em diversos campos de atuação para obter melhores resultados em projetos. Destaca-se ainda, a diminuição do tempo de serviço, a melhoria na produtividade da mão de obra, como na segurança do trabalho.

Cabe à ANAC tratar dos assuntos técnicos/operacionais voltados às condições das aeronaves (certificação, registro, cadastro técnico, etc) e à situação dos pilotos (licenças, requisitos, cadastros, etc) e caberia ao DECEA tratar do acesso ao espaço aéreo.

Quando essas diretrizes não forem obedecidas, ou os drones forem utilizados de maneira errônea, existem enquadramentos nos quais podem gerar penalidades para os responsabilizados. Como previsto no Código Penal (Decreto Lei no 2848), no Artigo 132, "expor a vida ou saúde de outrem a perigo direto e iminente", e no Artigo 261, "expor a perigo embarcação ou aeronave, própria ou alheia, ou praticar qualquer ato tendente a impedir ou dificultar navegação marítima, fluvial ou aérea [...] (BRASIL, 1940)." Conforme DECEA (2015, p.19) os cuidados na manipulação desses equipamentos é fundamental, pois a sua operação deverá priorizar a segurança, minimizando os riscos para outras aeronaves, para as pessoas presentes nas proximidades e propriedades particulares no solo. Isso nos remete a refletir a importância do piloto em comando como o elemento que intervém em uma situação para evitar um acidente.

O artigo 21, inciso XII, alínea "c", da Constituição Federal de 1988 (CF/88) dispõe que compete a União explorar diretamente ou mediante autorização, 
permissão ou concessão a navegação aérea. O conceito navegação aérea abarca diversas atividades, sendo que a competência da União - Comando da Aeronáutica (COMAER) - Departamento de Controle do Espaço Aéreo (DECEA) é no tocante a prover a segurança da navegação aérea.

A portaria da DAC 207 de 1997 estabelece as regras para a operação do aeromodelismo no Brasil - deve ser realizado até 400 pés (120 metros) de altura, em locais longes de áreas densamente povoadas, assim como, evitar o uso nas proximidades de urbanas sensíveis ao ruído produzido pela aeronaves como hospitais, templos religiosos, escolas e asilos, além de ter a o homologação da Agência Nacional de Telecomunicações (ANATEL).

A regra também proíbe a operação de aeromodelos nas zonas de aproximação e decolagem dos aeródromos e estabelece que os veículos rádio controlados, que não forem para esporte ou lazer, deverão ser submetidos à Anatel, à Agência Nacional de Aviação Civil (ANAC) e ao DECEA, respectivamente.

A publicação da ICA 100-40 - Sistemas de Aeronaves Remotamente Pilotadas e o Acesso ao Espaço Aéreo Brasileiro (DECEA, 2015), o que representa um marco regulatório nas atividades que envolvem Aeronaves Remotamente Pilotadas (ARPs).

Mesmo com a publicação da ICA 100-40, devemos entender que tal legislação não pode ser vista como definitiva, uma vez que está sob a sombra, principalmente, da evolução da tecnologia disponível e considerada segura. Dessa forma, pode-se afirmar que a legislação que trata do uso do espaço aéreo brasileiro por aeronaves remotamente pilotadas deve ser tratada como um "documento vivo", o qual necessita de constante revisão e adequação.

Para o desenvolvimento desta tecnologia, é imprescindível o cumprimento das legislações aplicáveis. Assim, é importante destacar o cumprimento das instruções do ICA 100-40 (DECEA, 2015), seguindo criteriosamente as regras exigidas em relação à documentação necessária antes e durante a execução dos voos.

Sendo estas, o cadastro do drone no Sistema de Aeronaves não Tripuladas (SISANT), o manual do equipamento, o seguro para danos causados a terceiros, a avaliação de risco operacional, a qual informa a probabilidade e severidade de 
riscos, além de comunicar medidas mitigatórias e a quem contatar em caso de ocorrência destes, e a autorização de acesso ao espaço aéreo emitida através do Solicitação de Acesso de Aeronaves Remotamente Pilotadas (SARPAS).

Um documento importante e que cabe atenção é o Decreto $n^{\circ} 8.764$ de 10 de maio de 2016 que institui o Sistema Nacional de Gestão de Informações Territoriais (SINTER) ao qual traz em seu Art. $1^{\circ}$ :

Fica instituído o Sistema Nacional de Gestão de Informações Territoriais (SINTER), ferramenta de gestão pública que integrará, em um banco de dados espaciais, o fluxo dinâmico de dados jurídicos produzidos pelos serviços de registros públicos ao fluxo de dados fiscais, cadastrais e geoespaciais de imóveis urbanos e rurais produzidos pela União, pelos Estados, pelo Distrito Federal e pelos Municípios (Brasil, 2016).

Esse documento revela que existe uma Instituição responsável pela salvaguarda de dados geoespaciais referente a imóveis urbanos e rurais ao qual o uso de ARP pode ter uma relação direta, visto que o seu uso já é considerado como uma ferramenta de obtenção de informações geoespaciais confiáveis e de precisão. O interessante é que o Art. 12 desse mesmo Decreto ainda informa que:

O SINTER disponibilizará aos registradores de imóveis e notório acesso a ferramenta gráfica de visualização dos polígonos limítrofes de imóveis sobrepostos às imagens georreferenciadas, e lhes permitirá obter informações cadastrais e geoespaciais de interesse para os atos praticados em suas serventias (Brasil, 2016).

Sendo assim, fica evidente que pode se tratar de uma aplicação do uso de ARP, pois as imagens captadas por essas aeronaves são capazes de identificar os imóveis ao qual estão submetidas.

Desta maneira, é de suma importância que as informações geradas com essas novas tecnologias sejam complementadas com medições convencionais a fim de se identificar o grau de precisão das mesmas ou até mesmo para validar as informações obtidas pela aerofotogrametria.

Cabe salientar que nas medições tradicionais, se utiliza de equipamentos compatíveis com as características dos levantamentos voltados ao georreferenciamento, como o Real Time Kinematic (RTK) ou Posicionamento Cinemático em Tempo Real, sendo esta uma técnica de posicionamento e 
navegação via Global Navigation Satellite System (GNSS), ou seja, Sistema Global de Navegação por Satélite, utilizada por sistemas como GPS, GLONASS, Galileo, Beidou entre outros.

A seguir, na Figura 2 apresenta-se as etapas metodológicas para o uso de um ARP, onde Silva et al. (2015b), apresenta o Planejamento de Voo; a Execução do Voo; as atividades necessárias do Pós Voo e a Avaliação da Acurácia.

Figura 2: Fluxograma dos Procedimentos Metodológicos para Aquisição, Processamento e Avaliação dos Dados Obtidos pelo ARP
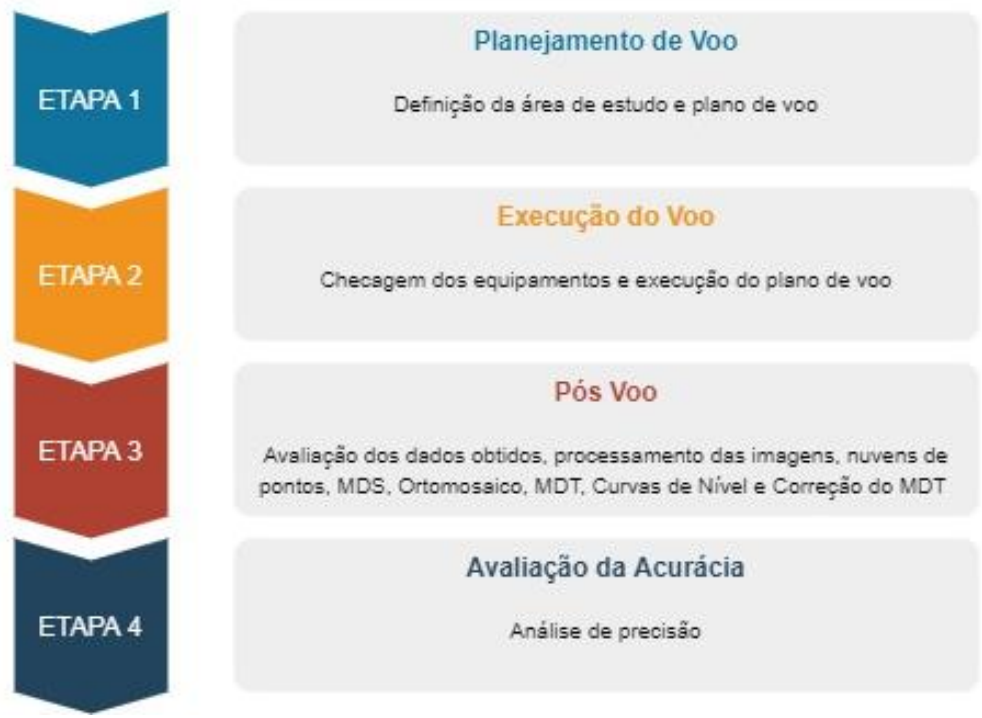

Fonte: Elaborado pelos autores (2019)

\section{RESULTADOS E DISCUSSÕES}

Para apresentar uma reflexão a respeito das aplicações dos drones, buscou-se apresentar alguns autores que, com seus diferentes enfoques práticos e objetivos, utilizaram-se da tecnologia ARP.

Assim, inicialmente, tem-se o empenho de VILAR (2019), que em seu, explicita características específicas, com a operação desempenhada pelo Visual Line-Of-Sight (VLOS), na qual o piloto mantém contato visual direto com a aeronave e esta, por sua vez, se enquadra na categoria ARP/RAPS, aeronave remotamente pilotada, pois é um equipamento que acessa o espaço aéreo sem a presença de um ser humano a bordo. 
No estudo de Schreiber \& Ostiari (2014), demonstra-se que, o maior mercado para o uso dos Drones, é na prática das forças armadas, entretanto, se tem um grande potencial de desenvolvimento (e de sustentabilidade econômica) na área da publicidade (propaganda e marketing), turismo e eventos, no controle epidemiológico da dengue inicialmente em larga escala pela vigilância sanitária, além da agricultura, segurança pública/privada, mapeamento, ou seja, os ARP têm amplos domínios de aplicação. Na esfera civil, eles são principalmente ferramentas de vigilância, intervenção ou assistência utilizadas na segurança pública, como por exemplo no monitoramento de áreas de ocupação urbana com fatores de risco; no Instituto Chico Mendes para Biodiversidade (ICMBio) na fiscalização das Unidades de Conservação (UCs) entre outros; bem como apoio técnico para pesquisadores nas mais diversas áreas da ciência. Várias são as aplicações na Engenharia Civil, tais como: Ensaio não destrutivo; Inspeção Predial; Monitoramento de Barragens; Terraplanagem; Segurança Pública, Vigilância Sanitária entre outras.

Os ensaios Não Destrutivos são definidos como testes para o controle da qualidade, realizados sobre produtos acabados ou semiacabados, para a detecção de falta de homogeneidade ou defeitos, através de metodologias bem definidas, sem prejudicar a posterior utilização dos produtos inspecionados. Constitui uma das principais ferramentas do Controle da Qualidade.

As anomalias e falhas constituem não conformidades que impactam na perda precoce de desempenho real ou futuro dos elementos e sistemas construtivos, e redução de sua vida útil projetada. Podem comprometer, portanto: segurança; funcionalidade; operacionalidade; saúde de usuários; conforto térmico, acústico e lumínico; acessibilidade, durabilidade, vida útil, dentre outros parâmetros de desempenho definidos na ABNT NBR 15575. As não conformidades podem estar relacionadas a desvios técnicos e de qualidade da construção e/ou manutenção da edificação.

Conforme (FEITAL, 2017, p.dd) as falhas podem ser classificadas em endógenas (originaria da própria edificação, como projeto, materiais e execução), exógena (originarias de fatores externos a edificação, provocadas por terceiros), natural (originaria de fatores da natureza), funcional (originária da degradação do sistema construtivo pelo envelhecimento natural) e falhas (podendo ser de 
planejamento, execução, operacional e gerencia).

De acordo com Normas temos a seguinte definição para Inspeção Predial: "Avaliação do estado da edificação e de suas partes constituintes, realizada para orientar as atividades de manutenção". Onde a Associação Brasileira de Normas Técnicas (ABNT) através da NBR 5674 "Verificação, através de metodologia técnica, das condições de uso e de manutenção preventiva e corretiva da edificação"; o que vem de encontro do emprego das técnicas de sensoriamento remoto via tecnologia ARP. Importante ressaltar, é que a norma de Desempenho a ABNT:NBR 15575, comtempla diversos ensaios que o Drone poderia acompanhar para inspeção/validação de uma obra juntamente as políticas públicas de habitação. Um dos exemplos de aplicação é a respeito das análise de infiltração e conforto térmico em edificações, onde o Drone juntamente com uma câmera termal acoplada, viabiliza a identificação e análises pertinentes a aspectos patológicos, juntamente com a inspeção supervisionada pelo profissional. Observa-se que, verificar as aplicações do uso de ARPs, vem auxiliar a interação dos profissionais da área de Engenharia Civil com o processo construtivo de edificações, com a finalidade de constatar o benefício de melhorar o método de trabalho, através da diminuição do tempo de serviço e dos riscos físicos dos profissionais envolvidos.

O uso de um ARP, ou seja, o uso de um dispositivo voador autônomo equipado com uma câmera filmadora/sensor e alguns acessórios, poderá ser aplicado para atender a diversas necessidades frente a obras de engenharia. A Lei n 12.334 de setembro de 2010 estabelece a Política Nacional de Segurança de Barragens (PNSB) e cria o Sistema Nacional de Informações sobre Segurança de Barragens (SNISB). Tal Lei tem aplicação sobre as barragens destinadas à acumulação de água, disposição de rejeitos e à acumulação de rejeitos industriais.

O Art. 9o descreve que "As inspeções de segurança regular e especial terão a sua periodicidade, a qualificação da equipe responsável, o conteúdo mínimo e o nível de detalhamento definidos pelo órgão fiscalizador em função da categoria de risco e do dano potencial associado à barragem". E os parágrafos 1, 2 e 3 do art. 9으, fazem referência ao conteúdo das inspeções e os relatórios gerados pelas mesmas (VEZENTAINER, 2018, p.16).

Peixoto (2018), apresenta experiência de sucesso do uso do drone para 
engenharia. O autor menciona que em seu trabalho, o objetivo foi simular um projeto de terraplanagem feito para a implantação de um condomínio residencial em área bastante irregular. Para tanto utilizou-se de um Modelo Digital do Terreno (MDT), com grande precisão, pois à partir dele foi feito a simulação do projeto de terraplanagem existente, com os devidos cortes longitudinais, cortes transversais e cálculo dos volumes de corte e aterro. O planejamento de voo foi feito para atender estas exigências.

Frente os exemplos mencionados de aplicações do RPA no contexto da Engenharia Civil, observa-se a necessidade de consolidar os conhecimentos técnicos científicos deste equipamento aerofotogramétrico na composição do perfil e das competências, estabelecidas para egressos de curso de graduação em Engenharia Civil. A relevância do tema RPA se dá por tratar-se de uma tecnologia recente, porém com uma gama de benefícios que poderá proporcionar a profissionais, como é o caso das áreas das engenharias. Sendo assim, é possível direcionar o tema à formação profissional do engenheiro civil devido as atribuições e competências técnicas desse profissional (TESTONI, 2018, p.04).

Bueno (2019), apresenta a fotogrametria digital na formação técnica do engenheiro civil, com enfoque empreendedor, voltada a sustentabilidade socioambiental, proposta na matriz do curso de Engenharia Civil da Universidade Alto Vale do Rio do Peixe (UNIARP), campus Caçador/SC. A autora propõe a integração do aluno na construção do conhecimento, a partir de um ambiente tecnológico teórico-prático, de uma postura proativa, contemporânea e participativa no processo da construção do conhecimento em engenharia. Assim, corroborar com a formação na área da engenharia, com o desenvolvimento do perfil e das competências, estabelecidas para o egresso do curso de graduação em Engenharia Civil, visando à atuação em campos da área e correlatos, conforme Associação Brasileira Mantenedoras de Ensino Superior (ABMES, 2019), podendo atender entre outras, as seguintes características:

- Estar apto a pesquisar, desenvolver, adaptar e utilizar novas tecnologias, com atuação inovadora e empreendedora;

- Ser capaz de reconhecer as necessidades dos usuários, formulando e analisando questões e resolvendo, de forma criativa, problemas de engenharia; 
- Formular, de maneira ampla e sistêmica, questões de engenharia, considerando o usuário e seu contexto, concebendo soluções criativas, bem como o uso de técnicas adequadas;

- Analisar e compreender os fenômenos físicos por meio de modelos simbólicos, físicos e outros, verificados e validados por experimentação:

- Ser capaz de modelar os fenômenos, os sistemas físicos, utilizando as ferramentas matemáticas, estatísticas, computacionais e de simulação, entre outras.

Tem-se que o mundo contemporâneo apela por novos paradigmas, novas categorias de pensamento, novas metodologias de pesquisa e novas formas de ensino (PHILIPPI JR., 2011). Como é o caso dos avanços tecnológicos do Sensoriamento Remoto na formação do conhecimento do engenheiro civil.

Entende-se que a respeito das reflexões sobre princípios de práticas interdisciplinares na pesquisa e no ensino superior, os processos de raciocínio, se diferem, assim como as metodologias adotadas. Muitas trabalham com as qualidades dos objetos que estudam, observando e descrevendo suas feições, classificando-as em função de suas semelhanças bem como suas diferenças, estabelecendo relações de causa e efeito entre eventos ou fatos. Visto que as especialidades científicas reúnem, instrumentos que servem para observar qualidades percebidas pelos sentidos; sendo que alguns servem para arranjar e classificar, outros para medir, outros para validar hipóteses relativas a eventos e/ou fenômenos naturais.

BUENO (2019), menciona que através das imagens digitais provenientes de um RPA, tem-se o apoio ao desenvolvimento de atividades de práticas de campo prevendo medições, identificação prévia da análise in loco de situações tanto de potencial de risco, quanto de efetivos de desastres naturais, um suporte as decisões de planejamento de ações de mitigação dos fenômenos. Oportunizando a identificação da localização dos fenômenos, área atingida, volume, topografia, áreas de entorno, malhas urbanas, lagos, restinga, baías entre outros. Destacandose a análise de indicativo de deslizamentos através de imagens digitais RPA como: declividade, elevação, cobertura do terreno e densidade de drenagem (com base nos parâmetros de caminho e direção de fluxo obtidos a partir do Modelo Digital de Elevação (MDE). Destacando-se no caso do planejamento de áreas passíveis a inundações, onde a partir dos dados provenientes das imagens Drone e o cruzamento destes através de sistema de informações territoriais, tem-se 
condições de realizar análises criteriosas quanto às instalações residenciais, segurança pública, análise diagnóstica de permissividade de uso entre outras (LONGLEY et al, 2013).

O domínio do potencial das tecnologias ARP, vem atender as demandas de estudos, análises, planejamento e gestão dos espaços. Com objetivo de buscar soluções sob o aspecto da sustentabilidade, para áreas de potencial de risco, como ocorrência de enchentes; deslizamentos de terra, entre outros. Corroborando-se com o previsto pela Agenda 2030 (ONU, 2015), reconhece-se que o desenvolvimento econômico e social depende da gestão sustentável dos recursos naturais do nosso planeta. Para tanto, aponta-se a necessidade de conservar e utilizar de forma sustentável os espaços, bem como promover entre outros a resiliência e a redução do risco de desastres naturais.

\section{CONSIDERAÇÕES FINAIS}

O presente artigo trouxe a luz algumas das aplicações dos ARPs, onde esta nova tecnologia está cada vez mais conectada, sem a pretensão de esgotar o tema. Com intuito de colaborar bibliograficamente em relação as reflexões para estudos posteriores, por ser uma tecnologia que vem cada vez mais desenvolvendo o aprimoramento de aplicações práticas relacionadas as atividades de engenharia.

O que confere no contexto do mercado da construção civil, gerando análises técnico-científicas e trazendo diversos benefícios desde a elaboração de projetos mais detalhados até a logística e gerenciamento de obras. Como também, fazer parte dos temas a serem trabalhados para o desenvolvimento do perfil e das competências, estabelecidas para o egresso do curso de graduação em Engenharia Civil, atendendo as expectativas do domínio tecnológico para a solução de problemas de engenharia, indicados pela (ABMES) de 2019. Já o Referencial Teórico abordou a tecnologia ARPs, apresentando suas normas de utilização (legislação vigente), critérios para inspeção de obra e a metodologia de ensaio a qual o uso dos ARPs se aplica, a de Ensaios não Destrutivos.

Dentre os inúmeros benefícios para área da Engenharia Civil, pode-se citar a garantia da qualidade dos serviços executados em obras, diminuindo a 
necessidade dos deslocamentos até o canteiro de obra, local da construção; o aumento da produtividade, elemento essencial para um mercado cada vez mais competitivo. Destaca-se a alta resolução e o nível de detalhamento das imagens capturadas por realizar voos mais baixos, comparando-as às imagens de satélite, além da facilidade para obtenção de imagens com valores mais acessíveis em relação aos levantamentos aerofotogramétricos tradicionais; diminuição de custos de mão de obra, entre outros.

\section{REFERÊNCIAS}

AGÊNCIA NACIONAL DE AVIAÇÃO CIVIL (ANAC). Portaria DAC 207 - Estabelece as Regras para a Operação do Aeromodelismo no Brasil. 1997. [On Line]. Disponível em: <https://www.anac.gov.br/assuntos/legislacao/legislacao-1/port207ste.pdf>. Acesso em: Acesso em: 24 abr. 2019.

AGÊNCIA NACIONAL DE AVIAÇÃO CIVIL (ANAC). Regulamento Brasileiro da Aviação Civil Especial - RBAC-E n94. [On Line]. Disponível em: <https://www.defesa.gov.br/arquivos/cartografia/dica/legislacao/rbac_e_94_ana c_02_05_2017.pdff>. Acesso em: 24 abr. 2019.

BARON, Douglas. Comparação de Levantamento Topográfico por Estação Total com Levantamento Aerofotogramétrico por DRONES. 98 f. TCC (Graduação) Curso de Engenharia Civil, Departamento de Engenharia Civil, FURB.

Blumenau/SC: 2019-1.

BILK, Rubens. Aplicabilidade da Norma de Desempenho NBR 15575 em uma Tipologia "Minha Casa Minha Vida" no Município de Blumenau/SC. 73 f. TCC (Graduação) - Curso de Engenharia Civil, Departamento de Engenharia Civil, FURB. Blumenau/SC: 2018-2.

BORGES, Rodrigo Cella \& SILVA, Sávio Torres da. Usos de Drones em Estudos Ambientais. 71 f. TCC (Graduação) - Curso de Engenharia Sanitária e Ambiental, Universidade Católica Dom Bosco, Campo Grande/MS: 2018-2. [On Line].

Disponível em:<https://www.researchgate.net/profile/Savio_Torres_Da_Silva/publication/33 0834388_USOS_DE_DRONES_EM_ESTUDOS_AMBIENTAIS/links/5c561a4892851c 22a3a4b516/USOS-DE-DRONES-EM-ESTUDOS-

AMBIENTAIS.pdf?origin=profileFeaturedResearchPublicationItem>. Acesso em: 10 
dez 2019.

BRASIL. Decreto Lei n2284, 07 de dezembro de 1940. Código Penal. [On Line]. Disponível em: <http://www. planalto.gov.br/ccivil_03/decretolei/del2848compilado.htm>. Acesso em: 24 abr. 2019.

BRASIL. Constituição da República Federativa do Brasil de 1988. Diário Oficial da União (DOU): 05 Out. 1988. [On Line]. Disponível em: <http://www.planalto.gov.br/ccivil_03/constituicao/constituicao.htm>. Acesso em: 24 abr. 2019.

BUENO, Liane da Silva. Fotogrametria digital: formação técnica, empreendedora, voltada a sustentabilidade ambiental e social na matriz do curso de Engenharia Civil da UNIARP campus Caçador/SC. In: Ignis. Volume 08, № 01, 2019. Disponível em: https://periodicos.uniarp.edu.br/index.php/ignis/article/view/2238. Acesso em: dez. 2019.

CIPRIANI, Guilherme Rodolfo. Análise do Coeficiente de Produtividade da Mão de Obra dos Serviços de Superestrutura de Fôrmas e Armação de Pilares, Vigas e Lajes de Edifícios Residenciais em uma Construtora no Município de Blumenau/SC. 94 f. TCC (Graduação) - Curso de Engenharia Civil, Departamento de Engenharia Civil, FURB. Blumenau/SC: 2018-2.

DEPARTAMENTO DE CONTROLE DO ESPAÇO AÉREO (DECEA). Sistemas de aeronaves remotamente pilotadas e o acesso ao espaço aéreo brasileiro. ICA 10040. Rio de Janeiro/RJ, p. 74. 2015. ICA 100-40: Sistemas de Aeronaves Remotamente Pilotadas e o Acesso ao Espaço Aéreo Brasileiro. 2015. [On Line]. Disponível em: <https://www.decea.gov.br/static/uploads/2015/12/Instrucao-doComando-da-Aeronautica-ICA-100-40.pdf>. Acesso em: Acesso em: 24 abr. 2019.

FEITAL, Marcelo Rosa. Uso de equipamentos robotizados para inspeção de Projetos de Construção Civil. 35 f. TCC (Graduação) - Curso de Pós-Graduação em Gerenciamento de Projetos, Pontifícia Universidade Católica de Minas Gerais, PUC-MG, Belo Horizonte/MG: 2017. [On Line]. Disponível em: <http://pmkb.com.br/uploads//tcc-marcelo-rosa-feital.pdf>. Acesso em: 24 abr. 2019.

NAÇÕES UNIDAS. Transformando Nosso Mundo: A Agenda 2030 para o Desenvolvimento Sustentável. Disponível em:

https://nacoesunidas.org/pos2015/agenda2030/. Acesso em: dezembro 2019. 
INTERNATIONAL CIVIL AVIATION ORGANIZATION (OACI). Doc 10019 AN/507 Manual on Remotely Piloted Aircraft Systems (RPAS). 1a Ed. 2015. [On Line]. Disponível em: <https://skybrary.aero/bookshelf/books/4053.pdf>. Acesso em: 24 abr. 2019.

PEIXOTO, Floriano. Artigo: Case de sucesso sobre o uso de Drones na Engenharia. [On Line]. Disponível em: <http://www.droneshowla.com/artigo-case-de-sucessosobre-o-uso-de-drones-na-engenharia>. Acesso em: 02 de jul. 2018.

PHILIPPI JR., Arlindo; SILVA NETO, Antônio J. Interdisciplinaridade em Ciência, Tecnologia \& Inovação. Barueri/SP: Manole, 2011.

PHILIPPI JR., Arlindo; FERNANDES, Valdir. Práticas da Interdisciplinaridade no Ensino e Pesquisa. Barueri/SP: Manole, 2015.

SCHREIBER L.; OSTIARI E. Game of drones: do civilian applications harbour opportunities for sustainable development? Mirova Responsible Investing. Paris/FR: mai. 2014. [On Line]. Disponível em:

<https://pdfs.semanticscholar.org/fa8c/ede8656e9695204075e011451023243df7 12.pdf>. Acesso em: 24 abr. 2019.

TESTONI, Leandro Eduardo. As principais aplicações do uso de VANT em processo construtivo. 70 f. TCC (Graduação) - Curso de Engenharia Civil, Departamento de Engenharia Civil, FURB. Blumenau/SC: 2018-1. [On Line]. Disponível em: <http://www.bc.furb.br/docs/MO/2018/364575_1_1.pdf>. Acesso em: 24 abr. 2019.

VEZENTAINER, Lucas Matheus. Utilização de veículos aéreos não tripulados (VANT's) como tecnologia auxiliar na inspeção de barragem. $66 \mathrm{f}$. TCC (Graduação) - Curso de Engenharia Civil, Departamento de Engenharia Civil, FURB, Blumenau/SC: 2018-1. [On Line]. Disponível em:

<http://www.bc.furb.br/docs/MO/2018/364572_11.pdf>. Acesso em: Acesso em: 19 abr. 2019.

VILAR, Bárbara. Estudo de Caso - Aplicação de Drones na Engenharia in: Anais do 12ㅇ Congresso Brasileiro de Inovação e Gestão de Desenvolvimento de Produto. Brasília/DF: Universidade de Brasília (UnB). 2019. [On Line]. Disponível em: $<$ http://pdf.blucher.com.br.s3-sa-east1.amazonaws.com/engineeringproceedings/cbgdp2019/87.pdf>. Acesso em: 20 nov. 2019. 